\title{
Synthesis of of isopropyl levulinate from furfural: Insights on a cascade production perspective
}

Hilda Gómez Bernal ${ }^{\mathrm{a}}$, Patricia Benito ${ }^{\mathrm{b}}$, Enrique Rodríguez-Castellón ${ }^{\mathrm{c}}$, Anna Maria RaspolliGalletti $^{\mathrm{a}^{*}}$, Tiziana Funaioli ${ }^{\mathrm{a}}$

${ }^{\mathrm{a}}$ Dipartimento di Chimica e Chimica Industriale, Università di Pisa, Via Giuseppe Moruzzi, 13, 56124 Pisa, Italy

bDipartimento di Chimica Industriale “Toso Montanari”, Università di Bologna, Viale Risorgimento 4, 40136, Bologna, Italy

${ }^{c}$ Departamento de Química Inorgánica, Facultad de Ciencias, Universidad de Málaga, 29071 Málaga, Spain

\begin{abstract}
The present work explores the production of isopropyl levulinate from furfural by a two-step microwave assisted cascade process. Furfural is a versatile biomass-derived industrial feedstock with high annual production volume. Alkyl levulinates are promising bio-based molecules with several applications in many sectors, in particular, as biofuels, blended with transportation fuels including biodiesel, these compounds can significantly reduce the formation of soot in engines. Thus, in the first step, the catalytic transfer hydrogenation of furfural to furfuryl alcohol was studied employing a simply "ad hoc" synthesized magnetically recoverable $\mathrm{Cu}$ catalyst and 2-propanol as H-donor. Subsequently, the alcoholysis of the previously obtained liquors rich in furfuryl alcohol or of neat furfuryl alcohol solutions to isopropyl levulinate was investigated using commercial solid acid catalysts such as niobium phosphate and Amberlyst sulfonic resins (A15 and A70).

The cascade process resulted feasible leading to good furfuryl alcohol yields in the transfer hydrogenation process with $\mathrm{Cu}-\mathrm{Fe}_{3} \mathrm{O}_{4}$ magnetic catalyst using much lower $\mathrm{Cu}$ to furfural molar ratios than commonly reported. The subsequent alcoholysis step of furfuryl alcohol-rich liquors was highly efficient with A70 resin even in presence of unreacted furfural from the first step.
\end{abstract}

Keywords: Biomass, furfural, furfuryl alcohol, isopropyl levulinate, catalytic transfer hydrogenation, alcoholysis.

\section{Introduction}


Nowadays the search for greener processes and sustainability has become a must. In line with this premise, biomass derived platform molecules, particularly if recovered from waste, represent a viable route for the transition from a fossil-based era into a green circular economy. Furan compounds, for instance, can be subsequently upgraded to a great variety of value-added chemicals. Furfural (F), with an annual production of more than 200000 tons per year [1], is the feedstock from which commercial furan derivatives stem from, and along with furfuryl alcohol (FA) constitute remarkable specialty and reactive solvents which confer interesting properties to resins such as corrosion resistance, stability at high temperature, excellent physical strength, etc. [2].

FA production utilizes $65 \%$ of the overall $\mathrm{F}$ produced [1]. Besides its extensive use in the production of resins, it is an important building block for the synthesis of several value added compounds as tetrahydrofurfuryl alcohol (THFA), levulinic acid (LA), fragrances and pharmaceuticals as ranitidine and vitamin C. Recently, FA has been used as precursor for the production of alkyl levulinates which are promising bio based molecules with several applications as intermediates to produce coatings, resins, anti-cancer agents, pesticides, insecticides, and in the fine chemical industry as flavouring and fragrances [3-6]. These compounds are regarded as green solvents due to their low vapor pressures, which allows their use in metallic surface degreasing processes instead of chlorinated solvents. Of particular interest are their properties as fuel additives, since alkyl levulinates can raise the oxygen content in gasoline to burn more completely and reduce the release of harmful gases and the formation of soot in engines.

First reports on alkyl levulinate production involved LA esterification with an alcohol in presence of acid catalysts such as $\mathrm{HCl}$ [7]. Revisited literature favors heterogeneous catalysts not only due to their simple separation from the reaction mixture but also to the lack of corrosion and disposal issues of solid acids, which are inherent problems to the use of mineral acids. Recently, FA has revealed itself as a better precursor for alkyl levulinates due to its easy accessibility from $\mathrm{F}$, lower cost, high alcoholysis reactivity and higher carbon economy $[8,9]$. The conversion of neat FA to alkyl levulinates in presence of $\mathrm{C}_{1}-\mathrm{C}_{4}$ alcohols has been tested with several catalysts such as sulfuric acid, metal salts, sulfonated carbons and resins, heteropolyacids, zeolites and metal oxides [3-6, 8-11]. Although this reaction leads to good yields, it is industrially more amenable to put off purifying procedures to the final product. Thus, several one pot processes for alkyl levulinate production are being studied starting from $\mathrm{F}$ or even from poly- and monosaccharides in alcoholic medium. Such an approach necessitates of bifunctional catalytic systems in order to hydrogenate $\mathrm{F}$ to FA and perform the acid catalyzed FA alcoholysis to the alkyl levulinate. Chen et al. [12] proposed a one pot process for the production of ethyl levulinate (EL) from F catalyzed by $2 \%$ wt. Pt nanoparticles supported on a $\mathrm{ZrNb}$ binary phosphate. The reaction was performed at $130^{\circ} \mathrm{C}$ with 
$5 \mathrm{MPa}$ of $\mathrm{H}_{2}$ pressure and reached complete $\mathrm{F}$ conversion and up to $76 \%$ EL after $6 \mathrm{~h}$ of reaction. In spite of the good results obtained with this system, the fact of integrating conventional reductive technologies in presence of molecular hydrogen, although technically viable, can be considered challenging in regard to process safety and economics. Instead, catalytic transfer hydrogenation (CTH) using alcohols as hydrogen donors reduces production costs and hazards regarding $\mathrm{H}_{2}$ handling, transportation and storage [13] and also renders the process more sustainable, since alcohols used could be derived from biomass avoiding petroleum derived $\mathrm{H}_{2}$. Moreover, the lack of high $\mathrm{H}_{2}$ pressure potentially enhances selectivity in hydrogenation and/or hydrogenolysis reactions. The unconverted alcohol could be recycled to the feed while the ketone/aldehyde could be also separated and integrated into other biorefinery processes involving carbon chain growth by condensation to give valuable jet fuels, as already proposed in furfural based integrated biorefineries $[1,14,15]$.

Moreover, also Chen et al. [16] studied $\mathrm{Nb}_{2} \mathrm{O}_{5}-\mathrm{ZrO}_{2}$ mixed oxide microspheres for producing isopropyl levulinate (iPrL) from furfural with 2-propanol as hydrogen donor and solvent. $\mathrm{ZrO}_{2}$ has higher activity in transfer hydrogenation and $\mathrm{Nb}_{2} \mathrm{O}_{5}$ provides relatively strong surface acidity. This process setup leads to $93 \% \mathrm{~F}$ conversion with $72 \%$ selectivity to $\mathrm{iPrL}$ at $180^{\circ} \mathrm{C}$, but presents some problems concerning recyclability of the catalyst.

Also, $\mathrm{Zr}$ /Al-containing silicates have been tested for F conversion to butyl levulinate displaying only up to $18 \%$ yield to the ester product after $24 \mathrm{~h}$ of reaction at $120^{\circ} \mathrm{C}$, due to simultaneous promotion of side reactions. It is to say that not even changing the substrate to FA brought about any improvement in levulinate yield [4].

In the field of transition metals-catalyzed processes, magnetically recoverable ( $\mathrm{Pd}, \mathrm{Ir}$ and $\mathrm{Fe}$ )exchanged beta zeolites have been prepared by Jorge et al. [17] following a quite complex procedure and tested in the one pot F conversion to isopropyl levulinate. Pd-exchanged catalysts, which afford simple separation from the reaction medium, showed almost full conversion to the levulinate product at $130^{\circ} \mathrm{C}$ and $24 \mathrm{~h}$ of reaction with conventional heating. The microwave assisted reaction displayed equal results after one $\mathrm{h}$ of reaction time, demonstrating the efficiency of microwave heating. However, also this catalyst presented issues on recyclability, showing a net decline in F conversion after the first recycle and a clear decrease in levulinate selectivity when performing the sole FA alcoholysis.

Hence, great advances have been performed on F and FA conversion to alkyl levulinates but still several drawbacks have to be overcome such as the use of highly diluted feedstocks, high catalyst loadings, recyclability, etc. Different process approaches can also be evaluated that could better meet industrial requirements, such as a cascade process for $\mathrm{F}$ valorization to alkyl levulinates has 
not been evaluated before. In this study, $\mathrm{F}$ transfer hydrogenation is attempted using a magnetically recoverable $\mathrm{Cu}-\mathrm{Fe}_{3} \mathrm{O}_{4}$ catalyst and 2-propanol as solvent and H-donor. Subsequently, FA alcoholysis is studied with commercial solid acids such as niobium phosphate and Amberlyst sulfonic resins to produce isopropyl levulinate (iPrL). The best catalyst was further employed to convert the obtained $\mathrm{CTH}$ liquors to $\mathrm{PPL}$. The whole cascade process approach is depicted in Scheme 1.

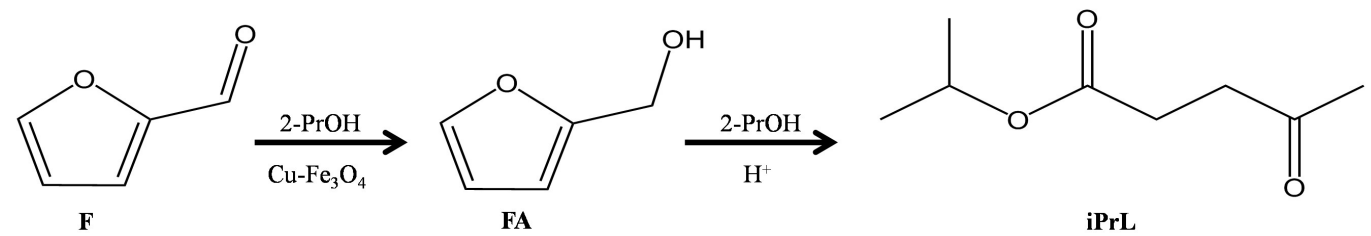

CT H

Alcoholysis

Scheme 1. Cascade process for furfural valorization to isopropyl levulinate.

Both steps are performed under microwave (MW) assisted heating, which can affords energy and time savings [18]. This last aspect is particularly relevant for laboratory-scale studies, allowing to perform a wide catalytic screening in a suitable time. Although mostly adopted on laboratory-scale, very recently the potential for scale-up of MW reactors has been considered for the catalytic valorization of biobased chemicals [19].

\section{Experimental}

\subsection{Materials}

Furfural (F, Sigma-Aldrich, 99\%), furfuryl alcohol (FA, Aldrich, 98\%), dodecane (Sigma-Aldrich, 99\%), 2-propanol (Merck, 99.8\% puriss p.a.), ethanol absolute anhydrous (Carlo Erba), iron(II) acetate $\left(\mathrm{Fe}\left(\mathrm{C}_{2} \mathrm{H}_{3} \mathrm{O}_{2}\right)_{2}\right.$, Aldrich, 95\%) and Amberlyst resins (A15 and A70, Rohm and Haas) were used as received. Niobium phosphate $(\mathrm{NbP})$ was kindly provided by CBMM (Companhia Brasileira de Metalurgia e Mineracão) and treated at $255^{\circ} \mathrm{C}$ for $6 \mathrm{~h}$ under high vacuum (5 Pa) before reaction.

The synthesis of the copper carbamate precursor $\left(\mathrm{Cu}_{2}\left(\mathrm{O}_{2} \mathrm{CNEt}_{2}\right)_{4} \cdot 2 \mathrm{NHEt}_{2}\right)$ and the magnetic materials $\left(\mathrm{Cu}-\mathrm{Fe}_{3} \mathrm{O}_{4}\right.$ and $\left.\mathrm{Fe}_{3} \mathrm{O}_{4}\right)$ are reported elsewhere [20, 21]. In particular, $\mathrm{Cu}-\mathrm{Fe}_{3} \mathrm{O}_{4}$ nanocatalyst was prepared by a green hydrothermal method consisting in the contemporaneous decomposition of iron(II) acetate and copper carbamate in $96 \%$ aqueous ethanol through MWirradiation at $120^{\circ} \mathrm{C}$ for 15 minutes. At the end of this treatment, the particles were magnetically 
collected, washed and dried [21]. Prior to catalytic tests the $\mathrm{Cu}-\mathrm{Fe}_{3} \mathrm{O}_{4}$ catalyst was reduced ex-situ in 2-propanol ( $13 \mathrm{mg}$ catalyst $/ \mathrm{ml})$ under $50 \mathrm{~atm} \mathrm{H}_{2}$ at $180^{\circ} \mathrm{C}$ for $5 \mathrm{~h}$.

\subsection{Catalyst characterization}

X-ray diffraction (XRD) analysis was carried out using a PANalytical X'Pert diffractometer equipped with a copper anode $\left(\lambda_{\text {mean }}=0.15418 \mathrm{~nm}\right)$ and a fast $X^{\prime}$ Celerator detector. Wide-angle diffractograms were collected over $2 \theta$ range from 5 to $70^{\circ}$ with a step size of $0.05^{\circ}$ and counting time $15 \mathrm{~s}$.

Micro-Raman measurements were performed in a Renishaw Raman Invia configured with a Leica DMLM microscope (obj. 5×, 20×, 50×). The available sources are an $\mathrm{Ar}^{+}$laser $\left(514.5 \mathrm{~nm}, \mathrm{P}_{\max }=30\right.$ $\mathrm{mW})$ and a diode-laser $\left(780.0 \mathrm{~nm}, \mathrm{P}_{\max }=300 \mathrm{~mW}\right)$. The system was equipped with edge filters to cut Rayleigh scattering, monochromators (1800 lines/mm for $\mathrm{Ar}^{+}$laser, and 1200 lines $/ \mathrm{mm}$ for diode laser) and a Charge-Coupled Device (CCD) thermoelectrically cooled (203 K) detector. Measurements were performed with the $\operatorname{Ar}^{+}$Laser $(514.5 \mathrm{~nm})$ at power level $\mathrm{P}_{\text {out }}=3 \mathrm{~mW}(10 \%$ power). Each spectrum was recorded by four accumulations ( $30 \mathrm{~s}$ for each).

X-ray photoelectron spectroscopy (XPS) studies were carried on a Physical Electronics PHI 5700 spectrometer with non-monochromatic $\operatorname{MgK} \alpha$ radiation $(300 \mathrm{~W}, 15 \mathrm{kV}$, and $1253.6 \mathrm{eV})$ with a multi-channel detector. Spectra were recorded in the constant pass energy mode at $29.35 \mathrm{eV}$, using a $720 \mu \mathrm{m}$ diameter analysis area. Charge referencing was measured against adventitious carbon (C $1 \mathrm{~s}$ at $284.8 \mathrm{eV}$ ). The spectrometer energy scale was calibrated using $\mathrm{Cu} 2 p_{3 / 2}, \mathrm{Ag} 3 d_{5 / 2}$, and $\mathrm{Au} 4 f_{7 / 2}$ photoelectron lines at 932.7, 368.2 and $84.0 \mathrm{eV}$, respectively. A PHI ACCESS ESCAV6.0 F software package was used for acquisition and data analysis. A Shirley-type background was subtracted from the signals. Recorded spectra were always fitted using Gaussian-Lorentzian curves in order to determine the binding energy of the different element core levels more accurately.

High resolution transmission electron microscopy (HRTEM) characterization was carried out by a TEM/STEM FEI TECNAI F20 microscope, equipped with an EDS analyzer. Powder catalysts were suspended in ethanol under ultrasounds for $20 \mathrm{~min}$. The suspension was subsequently deposited on multi foil carbon film $\mathrm{Au}$ grid and dried at $100{ }^{\circ} \mathrm{C}$ before doing the measurement. Particle size distribution was processed considering around 150 particles in three different zones for each sample.

Carbon and hydrogen analyses were performed on a Vario MICRO cube instrument (Elementar).

The metal content was determined by inductively coupled plasma-optical emission spectroscopy (ICP-OES) with a Spectro-Genesis instrument. 


\subsection{Catalytic tests}

The catalytic tests performed in this study were of two different types, namely CTH of $\mathrm{F}$ to yield FA and the subsequent alcoholysis of FA to yield iPrL. Both reaction setups were carried out under MW assisted heating, using a commercially available mono-mode MW unit (CEM Discover SP system) comprised of a calibrated external infrared sensor.

In a typical liquid phase $\mathrm{CTH}$ procedure, a $10 \mathrm{ml}$ glass reactor equipped with a magnetic Teflon stir bar was loaded with F $(0.25 \mathrm{~g}), 5 \mathrm{ml}$ of a $0.047 \mathrm{M}$ solution of dodecane, as internal standard, in 2-propanol and the desired amount of the copper catalyst. This procedure was carried out under an Ar atmosphere using standard Schlenk techniques and deaerated reagents and solvents. The reactor was capped inside the Schlenk and transferred to the MW unit to be heated to the desired temperature $\left(160-190^{\circ} \mathrm{C}\right)$ under maximum stirring at varying reaction times from 1 to four $\mathrm{h}$, at due time the reactor was rapidly cooled with an air jet.

Also, a comparative CTH test was performed in a conventionally heated and mechanically stirred Parr 4560 autoclave $(300 \mathrm{ml}$ ) equipped with a P.I.D. controller 4843 (comprising a thermocouple inside the autoclave). This reaction was performed loading $\mathrm{F}(2 \mathrm{~g})$ to $40 \mathrm{~mL}$ of a $0.047 \mathrm{M}$ solution of dodecane, in 2-propanol and the desired amount of the copper catalyst. The reactor was closed, purged three times with nitrogen and pressurized to 30 bar $\mathrm{N}_{2}$. After reaction time was finished, the reactor was rapidly cooled to room temperature.

To perform CTH recyclability tests, the spent catalyst was separated from the reaction solution with the aid of a magnet. The recovered $\mathrm{Cu}-\mathrm{Fe}_{3} \mathrm{O}_{4}$ catalyst was washed with deaerated 2-propanol under stirring and vacuum dried before adding the fresh reaction solution.

After the catalytic recycles, the catalyst was washed thoroughly with deareated acetone to remove organic matter deposited and vacuum dried before adding the fresh reaction solution.

FA alcoholysis in presence of 2-propanol was carried out in a $10 \mathrm{ml}$ glass reactor using either neat FA or FA-rich CTH liquors. In this case, $1.5 \mathrm{ml}$ of a $0.047 \mathrm{M}$ solution of dodecane (internal standard) in 2-propanol containing neat FA $(50 \mathrm{mg})$ or the FA-rich CTH liquor and the desired amount of the acid catalyst were fed into the reactor comprising a magnetic Teflon stir bar. The reaction mixture was $\mathrm{MW}$ heated to the desired temperature $\left(120-150^{\circ} \mathrm{C}\right)$ under maximum stirring at varying reaction times from 15 to $120 \mathrm{~min}$ and then cooled rapidly with an air jet.

A comparative FA alcoholysis test was carried out in a $10 \mathrm{ml}$ sealed glass vial comprising a magnetic stirring bar, heated in a conventional oil bath at $120^{\circ} \mathrm{C}$ for five hours of reaction time, using the same amounts of reagents stated for the MW assisted reaction. 
Alcoholysis recyclability tests were performed after washing twice the used resin with 2-propanol and then a 1:1 solution of 2-propanol/acetone under mixing for 30 minutes.

The reaction products were identified on an Agilent 7890B/5977A GC-MS with a HP-5MS column (Agilent Technologies, Palo Alto, CA, USA). Reagents and commercial products concentrations were analyzed using a DANI GC1000 gas chromatograph equipped with a flame ionization detector and Zebron capillary column (Methylpolysiloxane, $30 \mathrm{~m} \times 0.25 \mathrm{~mm} \times 0.25 \mu \mathrm{m}$ film thickness). Calibration curves of $\mathrm{F}$ and FA were performed using dodecane as internal standard for quantitative analysis. Non commercial products (iPrL and isopropyl furfuryl ether) were quantified obtaining the response factors from combined GC and NMR analyses. NMR spectra of the solutions were recorded at $298 \mathrm{~K}$ on a Bruker Avance II DRX400 instrument equipped with a BBFO broadband probe.

Heavy degradation products were not quantified. 2-furaldehyde diisopropyl acetal was identified by GC-MS but not quantified by GC due to its low amount.

Reagents conversions, yields and selectivity to products were defined as follows:

Conversions: $\mathrm{X}_{\text {Reagent }}(\mathrm{mol} \%)=\frac{\text { Moles of reagent reacted }}{\text { Moles of initial reagent }} \times 100$

Yields: $Y_{\text {Product }}(\mathrm{mol} \%)=\frac{\text { Moles of product formed }}{\text { Moles of initial reagent }} \times 100$

Selectivity: $\mathrm{S}_{\text {Product }}(\mathrm{mol} \%)=\frac{\text { Moles of product formed }}{\text { Moles of reagent reacted }} \times 100$

\section{Results and discussion}

\subsection{Liquid phase Catalytic Transfer Hydrogenation of furfural in presence of $\mathrm{Cu}-\mathrm{Fe}_{3} \mathrm{O}_{4}$ catalyst}

MW assisted F CTH to yield FA was carried out using 2-propanol as solvent and H-donor and the copper-based $\mathrm{Cu}-\mathrm{Fe}_{3} \mathrm{O}_{4}$ (denoted as $\mathrm{CuOx}[\mathrm{ca}] / \mathrm{Fe}_{3} \mathrm{O}_{4}$ in [21]) was tested as magnetically recoverable catalyst, at temperatures up to $190^{\circ} \mathrm{C}$. This catalyst was prepared by the MW assisted hydrothermal co-decomposition of $\mathrm{Cu}$ (II) carbamate and $\mathrm{Fe}(\mathrm{II})$ acetate precursors in alcoholic solvent. As previously reported, the presence of nanomagnetite was confirmed by XRD, Raman and IR data. Typical reflections of $\mathrm{CuO}$ were not detected by XRD presumably due to good $\mathrm{Cu}$ 
dispersion and low loading, however the presence of 3.9 wt.\% $\mathrm{Cu}$ was confirmed by ICP. XPS spectra indicated that the copper oxide on the catalyst surface was mostly $\mathrm{Cu}(\mathrm{II})$ along with a small amount of $\mathrm{Cu}(\mathrm{I})$.

Preliminary tests (not shown) with the as obtained catalysts at temperatures below $160^{\circ} \mathrm{C}$ resulted in minor catalyst activity, for instance at $150^{\circ} \mathrm{C}$ less than $10 \mathrm{~mol} \% \mathrm{~F}$ conversion and practically no FA yield was obtained after $1 \mathrm{~h}$ of reaction. Table 1 displays the results obtained from $160^{\circ} \mathrm{C}$ on. At $160^{\circ} \mathrm{C}$ and $1 \mathrm{~h}$ of reaction, the as obtained catalyst reaches $10 \% \mathrm{~F}$ conversion and a yield of $4 \% \mathrm{FA}$ is obtained. Further increasing temperature to $185^{\circ} \mathrm{C}$ and reaction time to $2 \mathrm{~h}, \mathrm{~F}$ conversion only reaches $14 \%$ and $10 \% \mathrm{FA}$ yield is obtained.

Table 1. Furfural $\mathrm{CTH}$ with $\mathrm{Cu}-\mathrm{Fe}_{3} \mathrm{O}_{4}$ at different conditions ${ }^{\mathrm{a}}$

\begin{tabular}{clccccc}
\hline Run F CTH & Pre- treatment & $\mathbf{T}\left({ }^{\circ} \mathbf{C}\right)$ & $\mathbf{t}(\mathbf{h})$ & $\mathbf{X}(\mathbf{m o l} \%)$ & $\mathbf{Y}_{\mathbf{F A}}(\mathbf{m o l} \%)$ & $\mathbf{S}_{\mathbf{F A}}(\mathbf{m o l} \%)$ \\
\hline 1 & - & 160 & 1 & 10 & 4 & 43 \\
2 & - & 185 & 2 & 14 & 10 & 75 \\
3 & reduced & 160 & 1 & 31 & 17 & 53 \\
4 & reduced & 160 & 2 & 38 & 27 & 70 \\
5 & reduced & 170 & 2 & 48 & 43 & 90 \\
6 & reduced & 180 & 2 & 61 & 56 & 92 \\
7 & reduced & 185 & 2 & 64 & 61 & 96 \\
8 & reduced & 190 & 2 & 55 & 47 & 86 \\
$9^{\text {b }}$ & Fe $\mathrm{O}_{4}$ & 185 & 2 & 25 & 14 & 54 \\
$10^{\mathrm{c}}$ & reduced & 185 & 2 & 35 & 31 & 90 \\
\hline
\end{tabular}

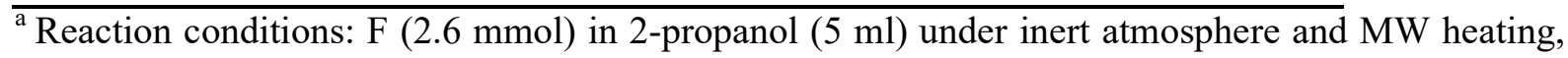
$\mathrm{F} / \mathrm{Cu}$ molar ratio of 86 which corresponds to an F/catalyst weight ratio of $5 .{ }^{\mathrm{b}} \mathrm{F} /$ catalyst weight ratio of $5 .{ }^{\mathrm{c}}$ Conventional heating under equal reaction conditions.

$\mathrm{Cu}$ based catalysts have often been proposed in a reduced state for the $\mathrm{F}$ transfer hydrogenation in alcohol. Villaverde et al. [22] states that metal copper is necessary for this reaction to occur at $110^{\circ} \mathrm{C}$ with $\mathrm{Cu}-\mathrm{Mg}$-Al catalysts and Scholtz et al. [23] reaches up to $28 \% \mathrm{FA}$ yields with a $\mathrm{Cu}-$ $\mathrm{Fe}_{2} \mathrm{O}_{3}$ catalyst at $180^{\circ} \mathrm{C}$ and $7.5 \mathrm{~h}$ of reaction time, stating that this catalyst is partially reduced in situ. Thus, the catalyst was reduced in autoclave with 2-propanol under $50 \mathrm{~atm}$ of $\mathrm{H}_{2}$ at $180^{\circ} \mathrm{C}$ for 5 h. After the pretreatment, the characterization of the catalyst confirms the reduction of $\mathrm{Cu}$. In the diffraction pattern (Fig. 1a), the small reflection at ca. $50.4^{\circ}(2 \theta)$ is related to the $(002)$ plane of $\mathrm{Cu}^{0}$ (note that the main $\mathrm{Cu}^{0}(111)$ reflection at $43.3^{\circ}(2 \theta)$ is overlapped with the (400) reflection of the magnetite spinel).While in the XPS spectrum, the low intensity $\mathrm{Cu} 2 p_{3 / 2}$ signal at $932.0 \mathrm{eV}$ could be 
related to $\mathrm{Cu}^{0}$ (Fig. 1c) $[24,25]$. The Auger $\mathrm{Cu}$ LMM signal was also recorded to determine the presence of $\mathrm{Cu}^{1+}$, but the very low intensity of the observed signal avoided to make any conclusion. The well dispersed copper species in the fresh catalyst were transformed into large particles with a broad size distribution $(89 \pm 37 \mathrm{~nm})$ after the reduction, which were deposited on the surface of the magnetite nanoparticles of $11 \pm 4 \mathrm{~nm}$. (Fig 2a, 2b, 2c). The cubic magnetite spinel structure is mostly intact according to XRD and Raman (Fig. 1a and 1b), though some large Fe particles are observed in the HRTEM images. These particles could be related to metallic iron since in the diffraction pattern the reflections at ca. 44.7 and $65.1^{\circ}(2 \theta)$ are due to the (011) and (002) planes of $\mathrm{Fe}^{0}$. The XPS Fe $2 p$ core level spectra only shows two peaks at binding energies 710.0 and 723.6 $\mathrm{eV}$ due to $\mathrm{Fe} 2 p_{3 / 2}$ and $\mathrm{Fe} 2 p_{1 / 2}$ in magnetite (Fig. 1d) $[26,27]$ and the peak at ca. $707.7 \mathrm{eV}$ due to $\mathrm{Fe}^{0}$ was not observed. The $\mathrm{O} 1 s$ signal was deconvoluted into two contributions at 529.8 and 531.7 $\mathrm{eV}$ (Fig. 1e). The former at low binding energy is close to that observed for lattice oxygen (530.2 $\mathrm{eV}$ ) of iron oxide. The latter at $531.7 \mathrm{eV}$, is assigned to hydroxyl species.
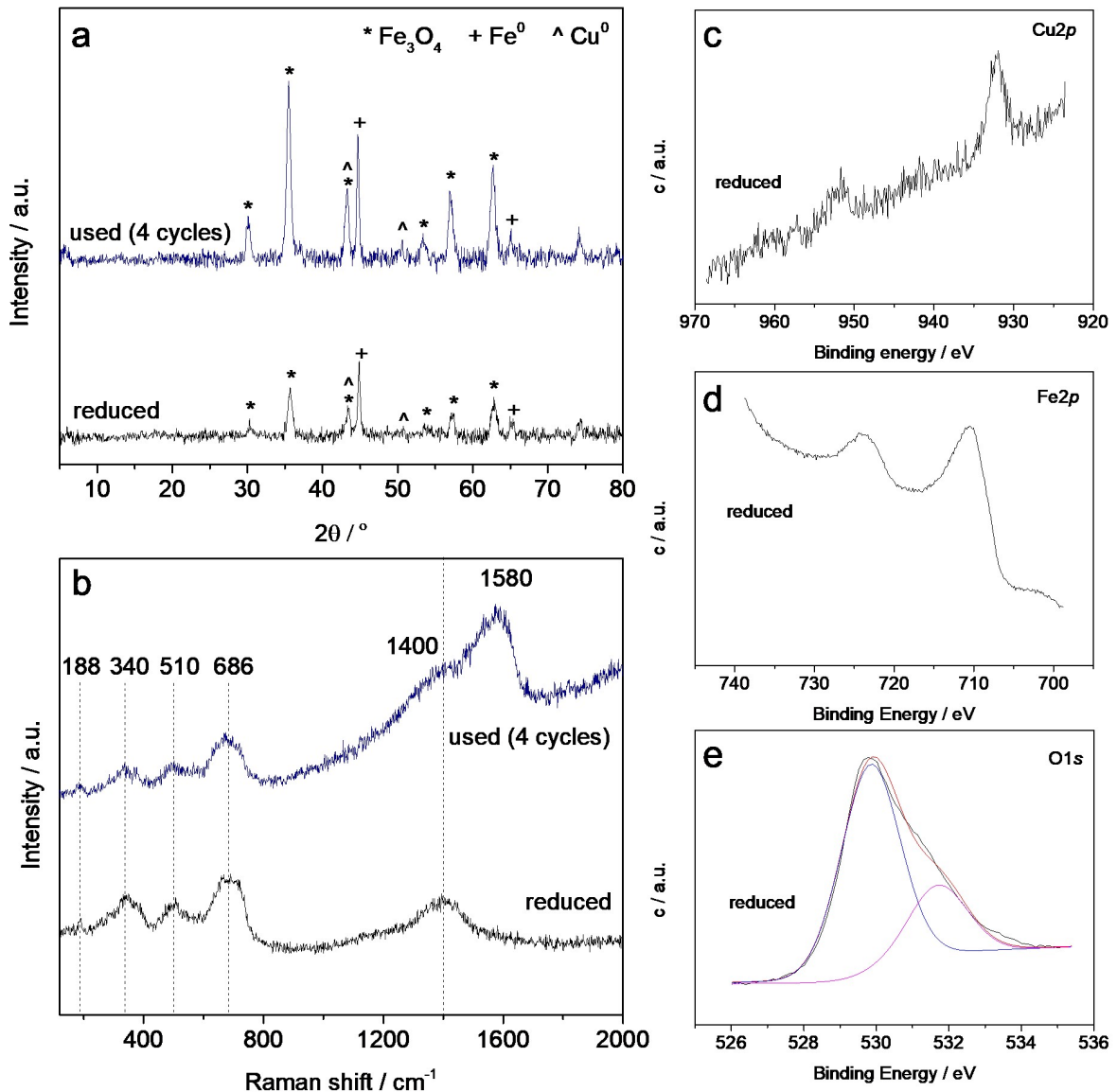

Figure 1. Characterization of reduced and used $\mathrm{Cu}-\mathrm{Fe}_{3} \mathrm{O}_{4}$ catalysts: a) XRD patterns; b) Raman spectra and c, d, e) XPS spectra for $\mathrm{Cu} 2 p, \mathrm{Fe} 2 p$, and $\mathrm{O} 1 s$, respectively. 


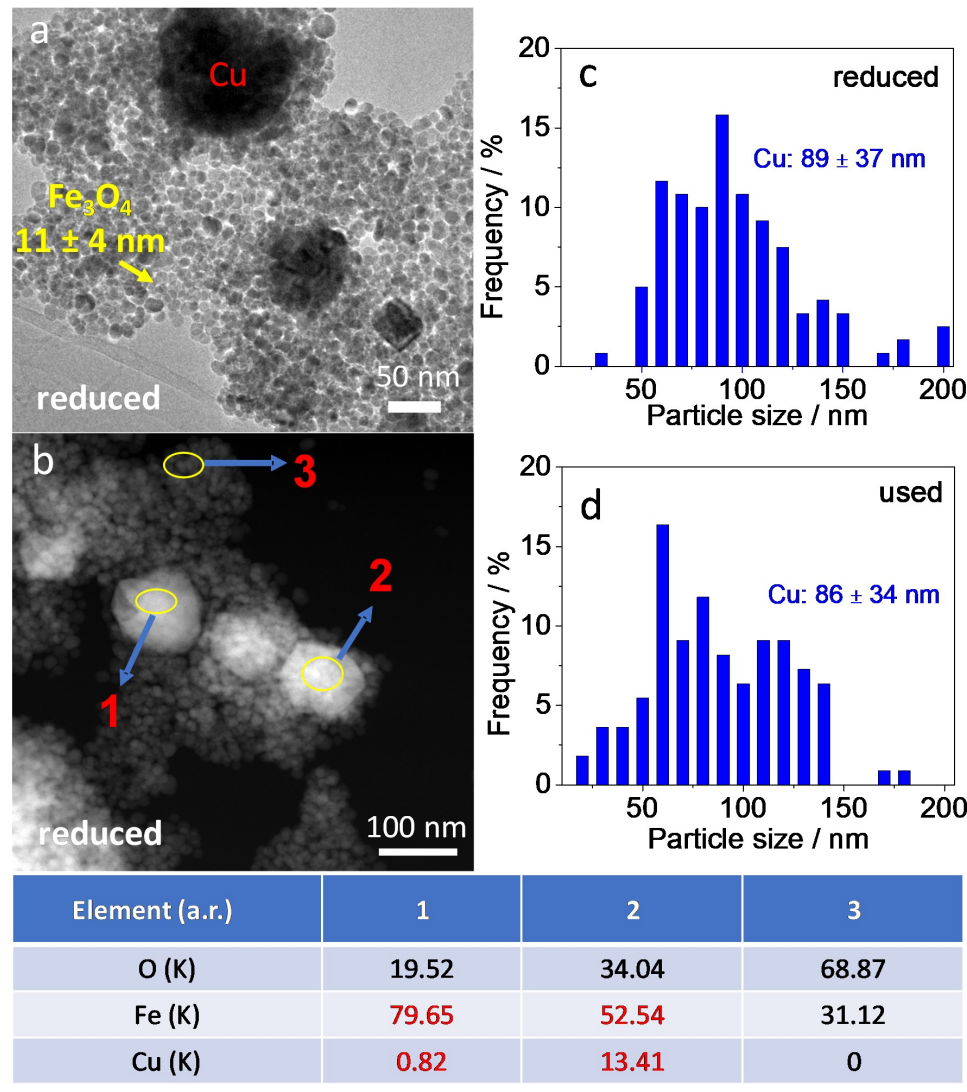

Figure 2. Characterization of reduced $\mathrm{Cu}-\mathrm{Fe}_{3} \mathrm{O}_{4}$ catalyst: a) HR-TEM image; b) STEM-HAADF image (element composition of each respective location is shown in the Table); c) $\mathrm{Cu}$ particle distribution; d) $\mathrm{Cu}$ particle distribution of used $\mathrm{Cu}-\mathrm{Fe}_{3} \mathrm{O}_{4}$ catalyst.

The reduced catalyst is noticeably more active already at $160{ }^{\circ} \mathrm{C}$ reaching $31 \% \mathrm{~F}$ conversion and $17 \% \mathrm{FA}$ yield after $1 \mathrm{~h}$ of reaction. Further prolonging reaction to $2 \mathrm{~h}, \mathrm{~F}$ conversion increases to $38 \%$ and a clear enhancement in FA selectivity is observed leading to $27 \%$ FA yield.

Increasing reaction temperatures results in higher catalyst activity up to $185^{\circ} \mathrm{C}$, which turned out to yield $61 \%$ FA with a $\mathrm{F}$ conversion of $64 \%$. The selectivity enhancement obtained by increasing reaction temperature is related to the reversible formation of 2-furaldehyde diisopropyl acetal, such formation is promoted at lower temperatures [28], while transfer hydrogenation is boosted at higher temperatures. Peculiarly, a slightly higher temperature of $190^{\circ} \mathrm{C}$ presented lower catalyst activity and selectivity probably due to $\mathrm{F}$ polymerization reactions leading to humins formation, known to be promoted at higher temperatures. Humins deposition on the catalyst surface partially deactivate the catalyst causing its lower activity. Then, in order to assess the contribution of the "support", bespoke magnetite synthesized as the copper-modified one [21] was tested at the best ascertained 
reaction conditions. Bare $\mathrm{Fe}_{3} \mathrm{O}_{4}$ presented higher activity than the non-reduced catalyst but lower FA selectivity, yielding only 14\% FA (run 9).

A comparative $\mathrm{CTH}$ test was performed with conventional heating and the same reaction conditions (run 10) showing a clear effect of microwaves mainly reducing reaction times.

Thus, the presence of reduced copper species in $\mathrm{Cu}-\mathrm{Fe}_{3} \mathrm{O}_{4}$ magnetic catalyst highly increases activity and selectivity (compare run 2 with 7) probably by activating 2-propanol through the metal hydride route [13]. Magnetite "support", as observed in run 9, also contributes to the catalyst activity perhaps by coordinating $\mathrm{F}$ through its carbonyl group on $\mathrm{Fe}^{2+} / \mathrm{Fe}^{3+}$ and also by facilitating the activation of the $\mathrm{O}-\mathrm{H}$ bond in 2-propanol due to the oxophilic nature of $\mathrm{Fe}$ [23]. It is remarkable that the activity of the as obtained $\mathrm{Cu}-\mathrm{Fe}_{3} \mathrm{O}_{4}$ is significantly lower respect to that of the reduced $\mathrm{Cu}-$ $\mathrm{Fe}_{3} \mathrm{O}_{4}$ system (compare run 2 and 7) so the presence of $\mathrm{Cu}^{0}$ has a marked effect on the enhancement of the selectivity to FA, confirming, as yet observed also for the runs 3 to 8 , that higher conversions determine also an increase of the selectivity, that reached $96 \%$ at the maximum conversion up here obtained of $64 \%$. It is strongly believed that intermediate formation of 2-furaldehyde diisopropyl acetal occurs at shorter reaction times which is successively hydrogenated to FA. Such acetal formation was confirmed by GC-MS.

As it was mentioned above, temperature has a clear effect increasing the reaction rate, reaching a maximum at $185^{\circ} \mathrm{C}$. The effect of reaction time was also analyzed and results are displayed in Figure 3.

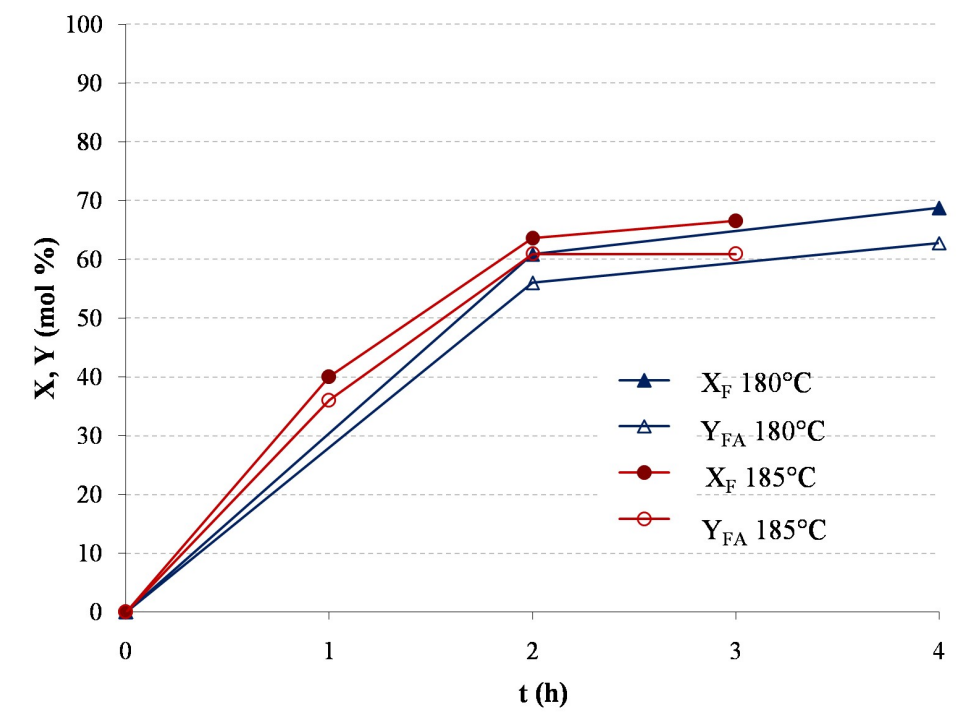

Figure 3. Liquid phase transfer hydrogenation of $\mathrm{F}$ to $\mathrm{FA}$ with $3.9 \mathrm{wt} \% \mathrm{Cu}-\mathrm{Fe}_{3} \mathrm{O}_{4}$ magnetic catalyst. Conversion and yield as a function of reaction time. Reaction conditions: F (2.6 mmol) in 2propanol (5 ml) under inert atmosphere, $\mathrm{F} / \mathrm{Cu}$ molar ratio of 86. 
A slightly lower reaction temperature $\left(180^{\circ} \mathrm{C}\right)$ leads to noticeable lower FA yields after $2 \mathrm{~h}$ of reaction and, in this case, longer reaction times result in higher FA yields. Instead, at the optimum temperature $\left(185^{\circ} \mathrm{C}\right)$ longer reaction times do not show any clear improvement on reaction yield, leading only to a slight increase in $\mathrm{F}$ conversion.

The effect of catalyst loading on the transfer hydrogenation of $\mathrm{F}$ was also studied. Three different catalyst loadings were tested, which account for $\mathrm{F}$ to $\mathrm{Cu}$ molar ratios from 171 to 43, the obtained results are displayed in figure 4, including a blank reaction for completeness. Reaction tests presented up to now were performed with a $\mathrm{F} / \mathrm{Cu}$ mol ratio of 86 . The blank reaction resulted mainly in F polymerization byproducts observed as a dark precipitate. When the amount of catalyst was halved, the catalytic activity was proportionally reduced, obtaining $38 \%$ of $\mathrm{F}$ conversion and $30 \%$ FA yield. When the catalyst was doubled ( $\mathrm{F} / \mathrm{Cu}$ mol ratio of 43 ), up to $71 \% \mathrm{FA}$ yield was obtained. In fact, at lower $\mathrm{F} / \mathrm{Cu}$ ratios the catalytic reaction consumes $\mathrm{F}$ more rapidly withdrawing it from degradation processes thus enhancing the selectivity to FA. It is to highlight that when quantitative FA yields have been reported in literature for the transfer hydrogenation of $\mathrm{F}$ with $\mathrm{Cu}$ based catalytic systems, these have always been obtained using quite higher metal loadings namely, $\mathrm{F} / \mathrm{Cu}$ mol ratio in the range of 10-1 and more diluted $\mathrm{F}$ solutions $(<2 \mathrm{wt} . \% \mathrm{~F})[22,29,30]$.

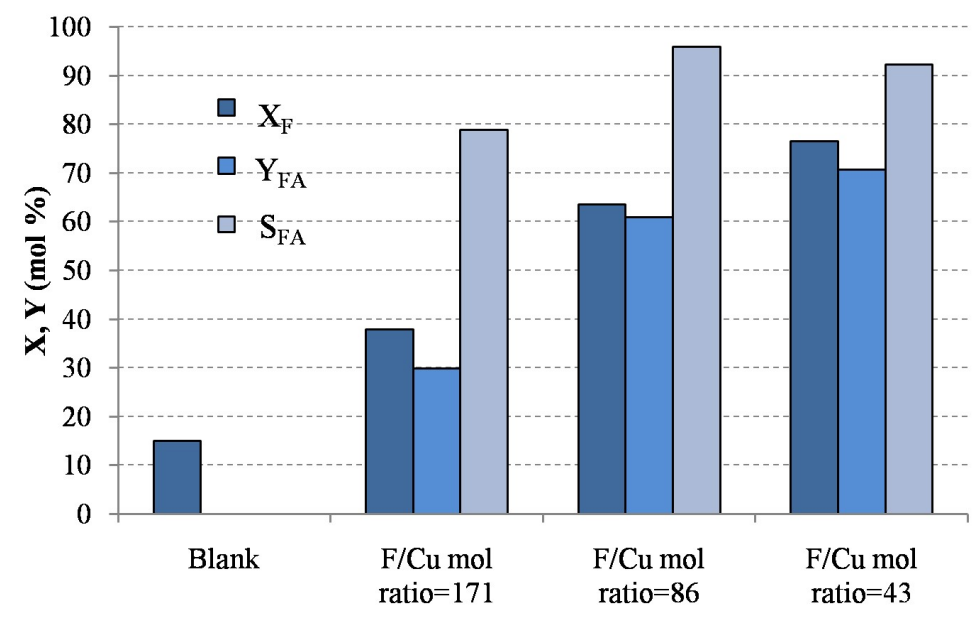

Figure 4. Influence of the catalyst loading on the $\mathrm{CTH}$ of $\mathrm{F}$ in presence of $3.9 \mathrm{wt} \% \mathrm{Cu}-\mathrm{Fe}_{3} \mathrm{O}_{4}$ magnetic catalyst. Reaction conditions: F $(2.6 \mathrm{mmol})$ in 2-propanol $(5 \mathrm{ml})$ under inert atmosphere for $2 \mathrm{~h}$ of reaction at $185^{\circ} \mathrm{C}$ using different $\mathrm{F}$ to $\mathrm{Cu}$ molar ratios.

To test catalyst stability in this reaction, four reaction cycles were performed (Fig. 5). After each test, catalyst and reaction liquors were separated with the aid of a magnet, under inert atmosphere. 
The catalyst was washed with 2-propanol and vacuum dried before adding fresh substrate in 2propanol.

The catalyst showed superior stability during the first three reaction cycles and only at the fourth one suffered from a $20 \%$ decrease in FA yield. Such decrease in catalyst activity can be most likely ascribed to organic matter deposition on the catalyst surface. In fact, the catalyst is stable in terms of structure and morphology. The diffraction pattern (Fig. 1a), Raman spectrum (Fig. 1b) and HRTEM images (Fig. S1) did not evidence significant modifications in $\mathrm{Fe}_{3} \mathrm{O}_{4}$ particles $(11 \pm 3 \mathrm{~nm})$, while the average $\mathrm{Cu}$ size is $86 \pm 34 \mathrm{~nm}$ after 4 cycles vs $89 \pm 37 \mathrm{~nm}$ in the reduced catalyst (Fig. $2 \mathrm{~d}$ and $\mathrm{c}$ ). The only difference observed in the catalyst after 4 reaction cycles is a Raman band at $1580 \mathrm{~cm}^{-1}$ due to $\mathrm{G}$ mode of carbon (Fig. 1b), in addition the carbon content of the spent catalyst was found to increase up to $4 \%$ (see supporting information for elemental analysis Table S1). The $\mathrm{Cu}-\mathrm{Fe}_{3} \mathrm{O}_{4}$ catalyst was then washed thoroughly with deareated acetone and vacuum dried. This led to good restoring of the catalytic sites as observed in fig. 5 .

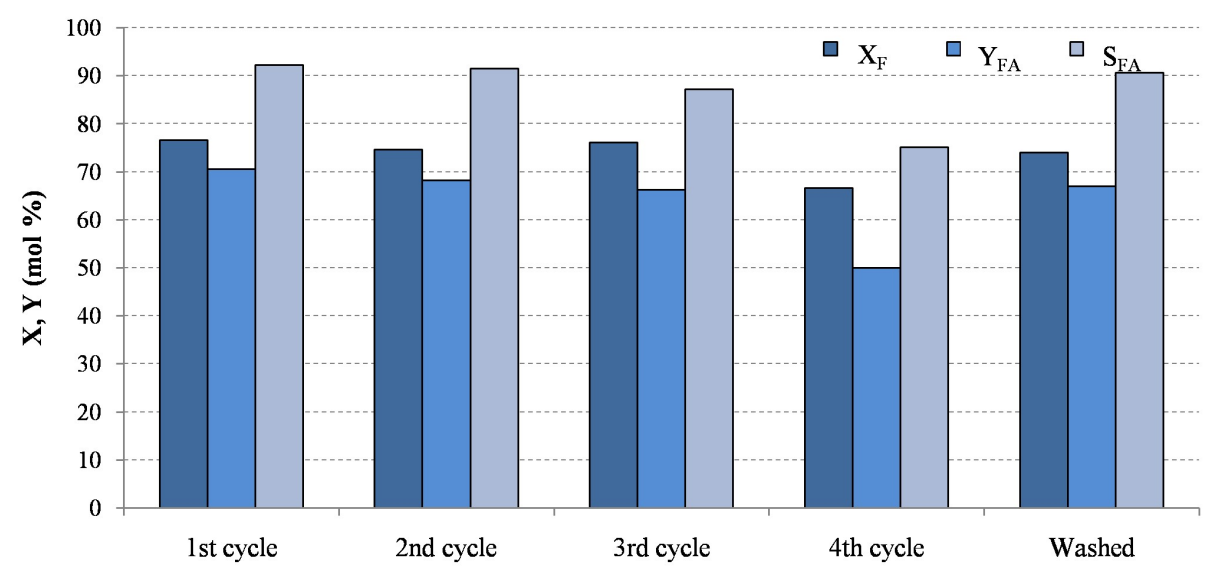

Figure 5. Recyclability test of the $3.9 \mathrm{wt} \% \mathrm{Cu}-\mathrm{Fe}_{3} \mathrm{O}_{4}$ magnetic catalyst. Reaction conditions: $\mathrm{F}$ (2.6 $\mathrm{mmol})$ in 2-propanol $(5 \mathrm{ml})$ with $\mathrm{F} / \mathrm{Cu} \mathrm{mol} \mathrm{ratio}=43$, under inert atmosphere for $2 \mathrm{~h}$ of reaction at $185^{\circ} \mathrm{C}$.

\subsection{Alcoholysis of furfuryl alcohol to yield isopropyl levulinate (iPrL)}

In the second stage of the MW assisted cascade process, the obtained CTH liquors rich in FA were converted into $\mathrm{PrL}$ in presence of solid acid catalysts.

Initially, in order to get a clearer picture of the alcoholysis reaction, neat FA in 2-propanol was used as substrate for the sake of simplicity. The first catalyst tested was niobium phosphate $(\mathrm{NbP}), \mathrm{a}$ solid acid active also in the acid hydrolysis of raw biomass. This catalyst presents both terminal 
$\mathrm{POH}$ and $\mathrm{NbOH}$ groups which behave as Brønsted acidic sites, whereas $\mathrm{Nb}^{5+}$ coordinatively unsaturated exposed sites confer Lewis acidity of medium strength; the acid capacity of this material is 0.33 meq $\mathrm{H}^{+} / \mathrm{g}[31,32]$. Table 2 presents the screening results of this catalyst with different loadings and different reaction temperatures.

Table 2. FA alcoholysis to $\mathrm{iPrL}$ in presence of $\mathrm{NbP}^{\text {a }}$

\begin{tabular}{lcccccc}
\hline run & $\mathrm{mmolFA} / \mathrm{meq}^{+}$ & $\mathrm{T}\left({ }^{\circ} \mathrm{C}\right)$ & $\mathrm{t}(\mathrm{min})$ & $\mathrm{X}(\%)$ & $\mathrm{Y}_{\mathrm{iPrFE}}(\%)$ & $\mathrm{Y}_{\mathrm{iPrL}}(\%)$ \\
\hline IL 1 & 50 & 120 & 15 & 40 & 36 & 4 \\
$\mathrm{IL} \mathrm{2}$ & 30 & 120 & 60 & 94 & 77 & 15 \\
IL 3 & 10 & 120 & 15 & 99 & 85 & 13 \\
IL 4 & 10 & 120 & 60 & 100 & 65 & 20 \\
IL 5 & 10 & 150 & 15 & 100 & 63 & 20 \\
IL 6 & 10 & 150 & 60 & 100 & 44 & 21
\end{tabular}

${ }^{\mathrm{a}}$ Reaction conditions: Neat FA $(0.51 \mathrm{mmol})$ in 2-propanol $(1.5 \mathrm{ml})$ under MW heating.

At $120^{\circ} \mathrm{C}$ and the lowest catalyst loading (run IL1) only $40 \%$ FA was converted reaching barely $4 \%$ yield of $\mathrm{iPrL}$ and $36 \%$ yield of isopropyl furfuryl ether (iPrFE), the latter has been reported as an intermediate for alkyl levulinate formation [33-35]. Increasing the amount of catalyst (run IL2) and reaction time to 60 min leads to a high increase in conversion up to $94 \%$ as well as higher yields of the ether product and $15 \%$ iPrL. The highest amount of catalyst (mmol FA/meq $\mathrm{H}^{+}=10$ ) leads to full conversion of FA already at $120^{\circ} \mathrm{C}$ but lower amounts of products (iPrFE+iPrL) are detected at long reaction times, meaning that significant degradation occurs. Still, the major product obtained is iPrFE. Increasing reaction temperature to $150^{\circ} \mathrm{C}$ with such high catalyst loading leads to a slight increase in the iPrL product, mostly at the expense of iPrFE (compare IL 3 with 5). Both reaction tests at this high temperature presented the highest amounts of degradation products, these being more pronounced at long reaction times. In any case, ether remains the major product obtained with this catalyst. It is worth noting that also alkyl furfuryl ethers are promising bio-based molecules with applications as flavors and fuel blends (up to $30 \% \mathrm{v} / \mathrm{v}$ ) in diesel engines $[4,36,37]$.

It has been reported that the conversion of the intermediate alkyl-furfuryl ether to alkyl levulinate presents quite low reaction rates [34] and that higher Bronsted acidity is needed for its conversion to the levulinate product [8]. Commercial ion exchange resins with sulfonated polymer frameworks present high Bronsted acid sites density; this type of resins have recently proven to be active in the esterification of levulinic acid with butanol [38]. 
Hence, two different sulfonic resins were tested, namely Amberlyst 15 (A15) and, Amberlyst 70 (A70). Their catalytic activity was analyzed during $2 \mathrm{~h}$ of reaction and the obtained kinetic profiles are shown in figure 6 . As observed in figure $6 \mathrm{~A}$, at $120^{\circ}$ with $6.4 \mathrm{mmolFA} / \mathrm{meq} \mathrm{H}^{+}, \mathrm{A} 15$ reaches almost full FA conversion already after 15 minutes of reaction. At this point, iPrFE presents a maximum in concentration which progressively decreases as reaction continues, displaying the typical behavior of an intermediate product, although without the initial induction time. After $2 \mathrm{~h}$ of reaction, $\mathrm{iPrL}$ yield reaches $78 \%$ and complete conversion of both FA and intermediate $\mathrm{iPrFE}$ is achieved.

Figure $6 \mathrm{~B}$ shows that $\mathrm{A} 70$ reaches total FA conversion also after $15 \mathrm{~min}$ of reaction, achieving $68 \%$ iPrL yield and less than 20\% iPrFE. Longer reaction times prompt to increasing iPrL yields, achieving up to $96 \%$ iPrL and practically no iPrFE.

A comparative reaction performed with conventional heating (not shown) leads to similar kinetic profiles but reaction times must be extended to five hours.
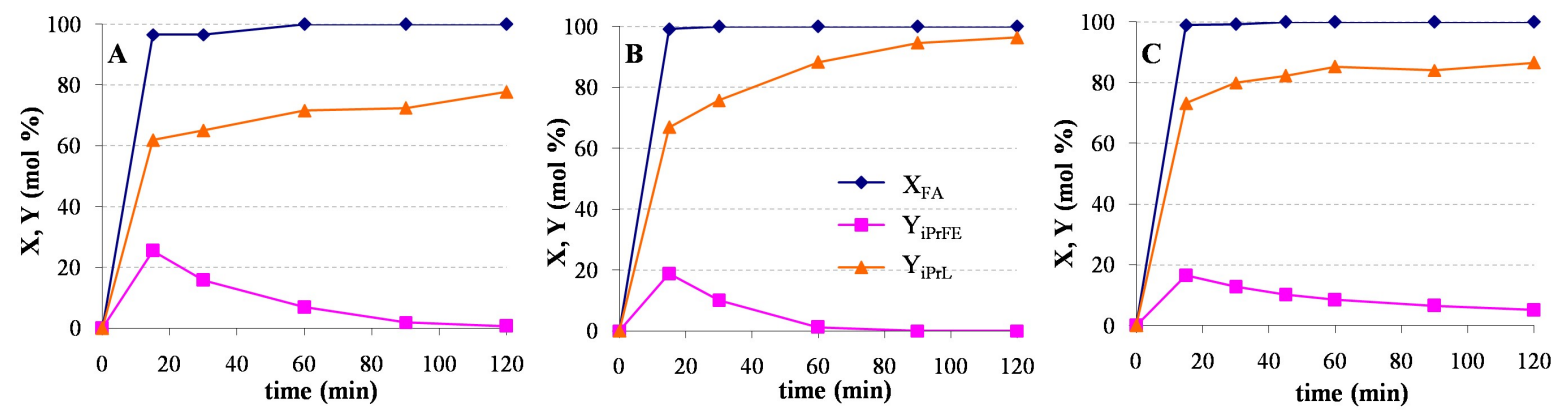

Figure 6. Kinetic profiles of FA alcoholysis at different temperatures in presence of A15 and A70: A) $120^{\circ} \mathrm{C}, \mathrm{A} 15$; B) $120^{\circ} \mathrm{C}, \mathrm{A} 70$; C) $150^{\circ} \mathrm{C}, \mathrm{A} 70$. Reaction conditions: FA (0.51 mmol) in 2propanol $(1.5 \mathrm{ml})$ with a substrate to catalyst ratio of $6.4 \mathrm{mmolFA} / \mathrm{meq} \mathrm{H}^{+}$.

A70 compared to A15, is a macroreticular styrene-divinilbenzene resin with lower cross-linking degree as well as lower acid capacity, that is 2.65 vs. $4.7 \mathrm{meq} \mathrm{H}^{+} / \mathrm{g}$, respectively. A15 instead, contains $20 \%$ divinylbenzene, which renders it less prone to swelling in the reaction medium [39]. Such a stiff matrix with high acid density might promote internal transport resistances and increase side reactions such as solvent etherification and FA polymerization/resinification, the latter observed by the darkening of the solution. It is to note that the FA concentration employed in this work is slightly higher than the ones frequently used in FA alcoholysis studies [3, 8-10, 33, 34]. Higher FA concentrations promote undesirable polymerization reactions, however, using more concentrated feedstocks is industrially desirable. 
A70 contains chlorine atoms in its structure which confer high thermal stability to this resin [39], so a higher reaction temperature was tested. The reaction performed at $150^{\circ} \mathrm{C}$ results in increased iPrL yield after 15 minutes of reaction as observed in figure $6 \mathrm{C}$. However, after $2 \mathrm{~h}$ of reaction, up to $87 \%$ iPrL yield is obtained but low amounts of iPrFE remain unreacted. The higher temperature probably enhances degradation reactions. For instance, 2-propanol dehydration to diisopropyl ether, although not quantified in this work, is clearly observed to increase with temperature in accordance with previous reports [9]. These side reactions probably compete with FA alcoholysis for acid sites, leading to lower iPrL yields at long reaction times.

The mechanism of FA alcoholysis catalyzed by Amberlyst sulfonic resins according to the literature $[34,35]$ is displayed in Scheme 2. As shown, different pathways are possible for the alkyl levulinate formation but all of them are initiated from the Bronsted acid addition to FA which causes the protonation of the hydroxyl moiety. The protonated FA can evolve completely detaching water and adding one alcohol molecule to form A (alkyl-furfuryl ether) or adding three alcohol molecules to form B which were both observed and identified as intermediates in the alkyl levulinate synthesis.

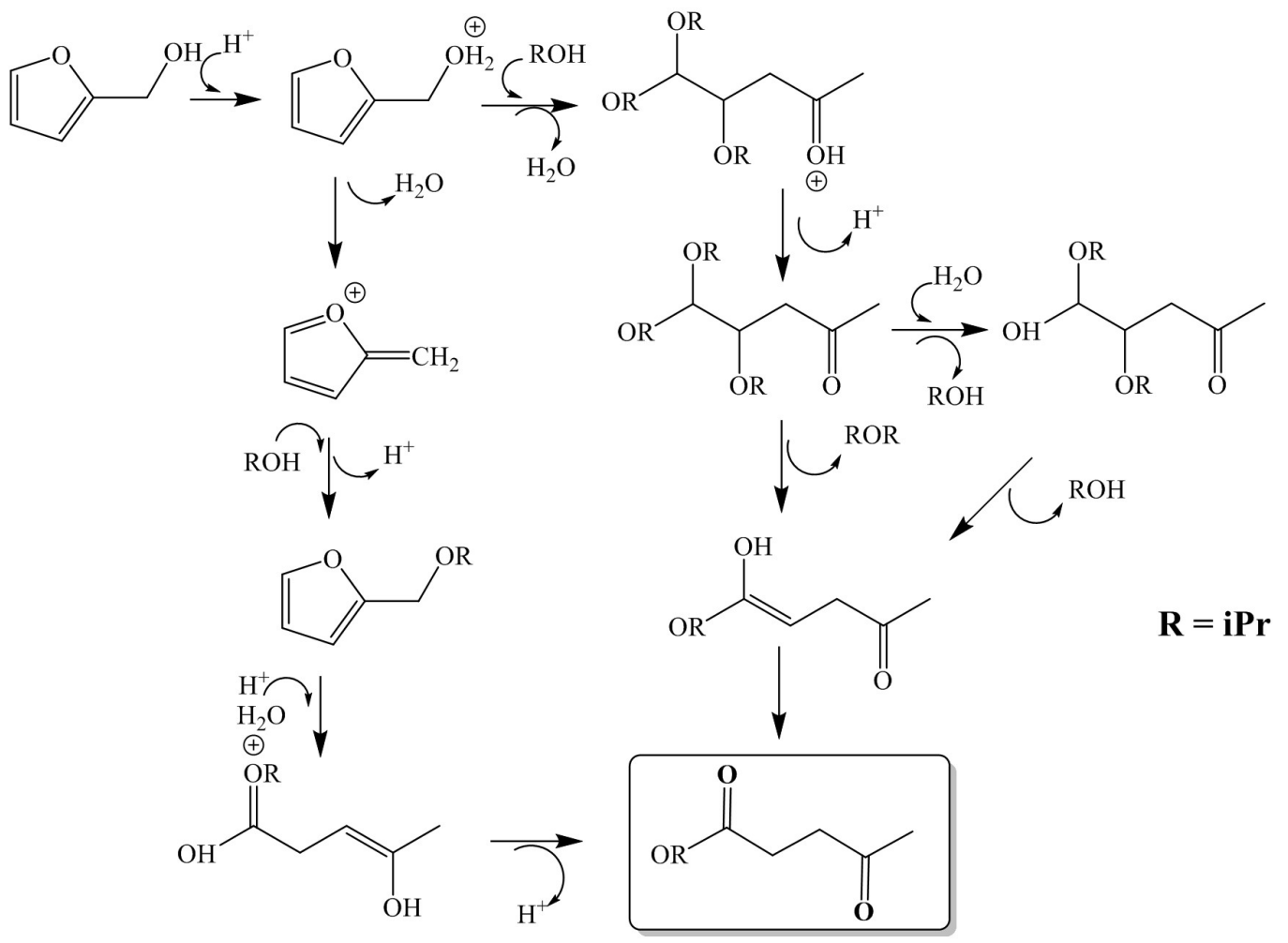

Scheme 2. Proposed reaction mechanism for FA alcoholysis. 
Recyclability of A70 was evaluated after washing the resin with 2-propanol and acetone. Two recycles were performed at $120^{\circ} \mathrm{C}$, showing good stability of the resin also at the third use, as observed in Fig. 7.

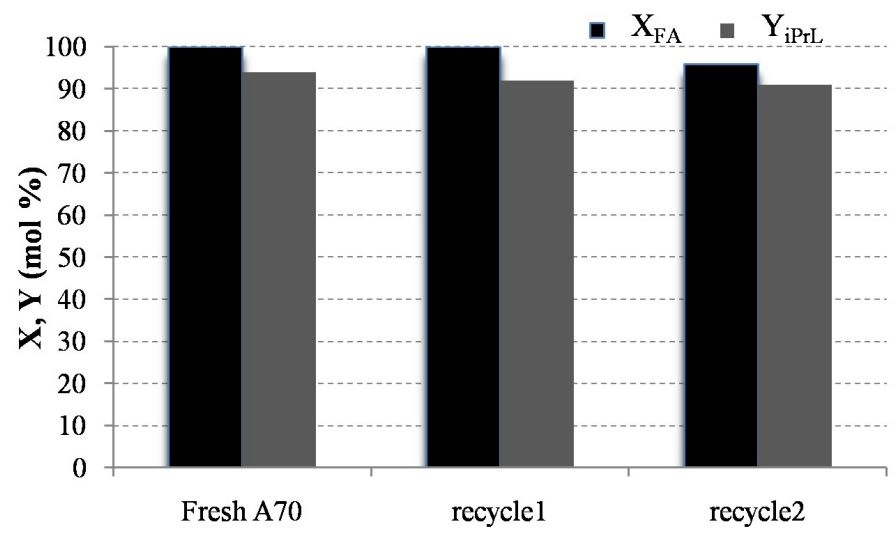

Figure 7. Recyclability of $\mathrm{A} 70$ at $120^{\circ} \mathrm{C}$ after $1.5 \mathrm{~h}$ of reaction. Reaction conditions: FA (0.51 $\mathrm{mmol})$ in 2-propanol $(1.5 \mathrm{ml})$ with a substrate to catalyst ratio of $6.4 \mathrm{mmol} \mathrm{FA} / \mathrm{meq} \mathrm{H}^{+}$.

Therefore, A70 showed excellent catalytic activity and stability at $120^{\circ} \mathrm{C}$, reaching up to $96 \%$ iPrL yield after $2 \mathrm{~h}$ of reaction employing a substrate to catalyst ratio of $6.4 \mathrm{mmol} \mathrm{FA} / \mathrm{meq}^{+}$and a FA concentration of $0.34 \mathrm{M}$. These reaction conditions were adopted for the conversion of FA-rich CTH liquors, which contain mainly FA and unreacted $\mathrm{F}$ in concentrations of $0.37 \mathrm{M}$ and $0.13 \mathrm{M}$, respectively. Selectivity to FA in the CTH reactions was usually over $90 \%$, so only little amounts of byproducts are present, among them, 2-furaldehyde diisopropyl acetal was qualitatively detected by GC-MS.

To better understand the role of unconverted $\mathrm{F}$ in the $\mathrm{FA}$ alcoholysis of raw liquors to $\mathrm{iPrL}$, a model solution of FA + F was employed as substrate, keeping the same $\mathrm{FA} / \mathrm{H}^{+}$molar ratio. The results are displayed in figure 8A. It was observed that $\mathrm{F}$ itself slightly lowers the yields of isopropyl levulinate. In fact a $\mathrm{F}$ conversion of nearly $40 \%$ was observed in this test, indicating a clear interaction of $\mathrm{F}$ and the active acid sites of the catalyst. At these reaction conditions, $\mathrm{F}$ conversion only leads to degradation products and small amounts of acetal remain. It is also interesting to note that although the total mmol of substrates $(\mathrm{F}+\mathrm{FA})$ to meq $\mathrm{H}^{+}$was increased to 9 , the catalyst activity remains high reaching total FA conversion, yet iPrL yields decreased to $81 \%$ after $1.5 \mathrm{~h}$.

On the base of the previous results, A70 was tested in the alcoholysis of FA-rich CTH liquors. It can be observed in figure $8 \mathrm{~B}$ that up to $84 \%$ yield of $\mathrm{iPrL}$ can be obtained, a very interesting performance considering the use of raw substrate. As above observed on the FA + F model solution, 
CTH liquors lead to somewhat lower iPrL yield respect to the use of neat FA, mainly due to the interaction of $\mathrm{F}$ with the acid catalyst, as confirmed by the high $\mathrm{F}$ conversion (up to 53\%). Moreover, small amounts of furfurylideneacetone were found among the unquantified byproducts due to condensation of $\mathrm{F}$ and acetone in $\mathrm{CTH}$ liquors in presence of the acid catalyst.
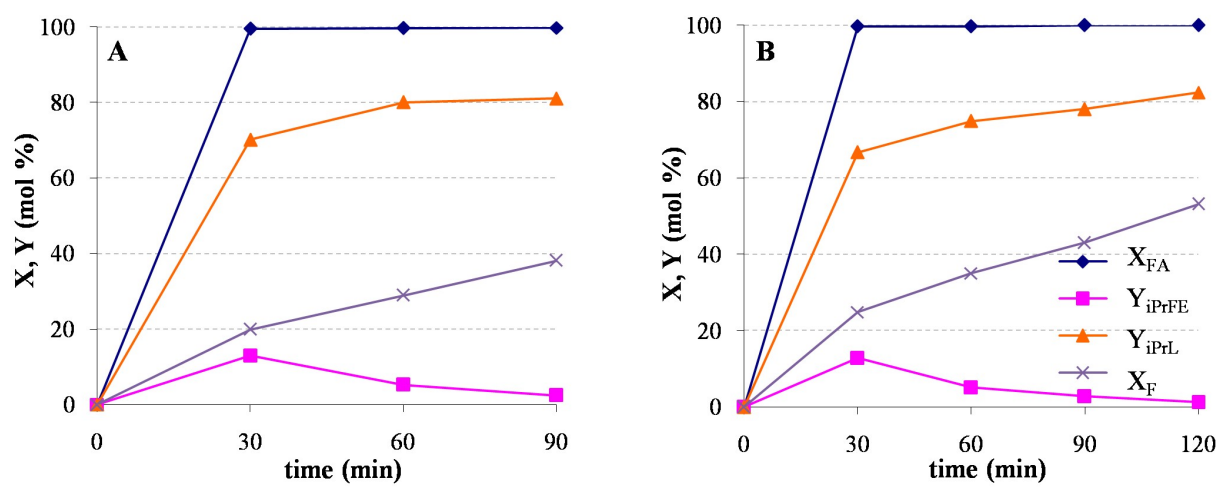

Figure 8. Alcoholysis of FA-rich liquors in presence of A70 at $120^{\circ} \mathrm{C}$. A) Effect of $\mathrm{F}$ addition on the kinetic profiles of FA alcoholysis. Reaction conditions: FA $(0.51 \mathrm{mmol})$, and F $(0.21 \mathrm{mmol})$ in 2-propanol $(1.5 \mathrm{ml})$ with a substrate to catalyst ratio of $6.4 \mathrm{mmol} \mathrm{FA} / \mathrm{meq} \mathrm{H}^{+}$; B) Alcoholysis of FA-rich CTH liquors. Reaction conditions: FA $(0.56 \mathrm{mmol})$ and F $(0.2 \mathrm{mmol})$ in 2-propanol $(1.5$ $\mathrm{ml}$ ) with a substrate to catalyst ratio of $6.9 \mathrm{mmol} \mathrm{FA} / \mathrm{meq} \mathrm{H}^{+}$.

The obtained result is quite promising since it demonstrates the possibility of reaching high isopropyl levulinate yields from FA rich streams in the presence of simple commercial sulfonic resins, without the intermediate expensive FA isolation. Furfural, mainly derived from the C5 sugars in the hemicellulose fraction, is a large scale biomass-platform and its upgrading to alkyl levulinates is highly desirable, specially from an integrated biorefinery viewpoint. The pentose fraction exploitation would increase the overall yield of an alkyl levulinate production plant from lignocellulose [40], taking into account the high research efforts that have recently been devoted to the one pot production of alkyl levulinates directly from hexose sugars, which requires quite well tuned acid catalysts to perform dehydration, etherification and ring opening reactions [41, 42].

\section{Conclusions}

A promising two step MW-assisted cascade process for upgrading furfural to isopropyl levulinate was studied. In the first step, consisting in the transfer hydrogenation of furfural with simply selfsynthesized $\mathrm{Cu}-\mathrm{Fe}_{3} \mathrm{O}_{4}$ magnetic catalyst, up to $71 \%$ molar yield of furfuryl alcohol was obtained using 2-propanol as solvent and hydrogen donor, working with a high furfural/Cu molar ratio and 
adopting an appreciable furfural starting concentration. The need of reduced $\mathrm{Cu}$ species was ascertained by catalytic reactivity tests. The magnetic catalyst showed good stability in four reaction cycles and, although organic matter deposition occurred, simple washing with acetone restored the catalytic sites.

The obtained FA-rich CTH liquors were successfully converted to isopropyl levulinate with Amberlyst 70 sulfonic resins displaying molar yields up to $80 \%$, showing the robustness of this commercial resin although in presence of unreacted and highly labile furfural.

The most remarkable feature of the proposed cascade process is that adequate tuning of each catalytic step avoids irreversible passivation of both catalysts used which is a common issue of the involved reactions.

The alcoholysis of neat FA was also performed with niobium phosphate, A15 and A70. Niobium phosphate displayed high activity in FA conversion leading to quite high and selective yields of isopropyl furfuryl ether intermediate (up to $85 \%$ yield and $86 \%$ selectivity) while the stronger Bronsted acidity of Amberlyst sulfonic resins resulted in high yields of the levulinate product. It was also observed that the resin with higher acid site density and higher crosslinking degree (A15) led to lower isopropyl levulinate yields perhaps due to transport hindrances given the more stiff matrix.

\section{Acknowledgements}

The authors thank Guido Pampaloni for providing copper carbamate.

\section{References}

1. R. Mariscal, P. Maireles-Torres, M. Ojeda, I. Sádaba and M. López Granados, Energy Environ. Sci., 9 (2016) 1144-1189.

2. H.E. Hoydonckx, W.M. Van Rhijn, W. Van Rhijn, D.E. De Vos and P.A. Jacobs, Furfural and Derivatives, Wiley-VCH Verlag GmbH \& Co. KGaA, Weinheim, 2012.

3. S.S. Enumula, K.S. Koppadi, V.R. Babu Gurram, D.R. Burri, S.R. Rao Kamaraju, Sustainable Energy Fuels, 1 (2017) 644-651.

4. M.M. Antunes, S. Lima, P. Neves, A.L. Magalhae, E. Fazio, F. Neri, M.T. Pereira, A.F. Silva, C.M. Silva, S.M. Rocha, M. Pillinger, A. Urakawa, A.A. Valente, Appl. Catal. B: Environ., 182 (2016) 485-503.

5. A. Demolis, N. Essayem, F. Rataboul, ACS Sustain. Chem. Eng., 2 (2014) 1338-1352.

6. E. Ahmad, M.I. Alam, K.K. Pant, M.A. Haider, Green Chem., 18 (2016) 4804-4823. 
7. P.P.T. Sah, S.Y. Ma, J. Am. Chem. Soc., 52 (1930) 4880-4883.

8. Y.B. Huang, T. Yang, M.C. Zhou, H. Pan, Y. Fu, Green Chem., 18 (2016) 1516-1523.

9. M. Paniagua, J.A. Melero, J. Iglesias, G. Morales, B. Hernández, C. López-Aguado, Appl. Catal. A: Gen., 537 (2017) 74-82.

10. P. Neves, S. Lima, M. Pillinger, S. M. Rocha, J. Rocha, A. A. Valente, Catal. Today, 218219 (2013) 76-84.

11. P. Neves, P.A. Russo, A. Fernandes, M.M. Antunes, J. Farinha, M. Pillinger, M.F.Ribeiro, J.E. Castanheiro, A.A. Valente, Appl. Catal. A: Gen., 487 (2014) 148-157.

12. B. Chen, F. Li, Z. Huang, T. Lu, Y. Yuan, G. Yuan, ChemSusChem, 7 (2014) 202-209.

13. M.J. Gilkey, B. Xu, ACS Catal., 6 (2016) 1420-1436.

14. H. Olcay, A.V. Subrahmanyam, R. Xing, J. Lajoie, J.A. Dumesic, G.W. Huber, Energy Environ. Sci., 6 (2013) 205-216.

15. J. Yang, N. Li, S. Li, W. Wang, L. Li, A. Wang, X. Wang, Y. Cong, T. Zhang, Green Chem., 16 (2014) 4879-4884.

16. B. Chen, F. Li, Z. Huang, G. Yuan, J. Energy Chem., 25 (2016) 888-894.

17. E.Y.C. Jorge, T.M. Lima, C.G.S. Lima, L. Marchini, W.N. Castelblanco, D.G. Rivera, E.A. Urquieta-González, R. S. Varma, M.W. Paixão, Green Chem., 19 (2017) 3856-3868.

18. C. Antonetti, M. Melloni, D. Licursi, S. Fulignati, E. Ribechini, S. Rivas, J.C. Parajó, F. Cavani, A.M. Raspolli Galletti, Appl. Catal. B: Environ., 206 (2017) 364-377.

19. P. Priecel, J.A. Lopez-Sanchez, ACS Sustainable Chem. Eng., 7 (2019) 3-21.

20. E. Agostinelli, D. Belli Dell’Amico, F. Calderazzo, D. Fiorani, G. Pelizzi, Gazz. Chim. Ital., 118 (1988) 729.

21. N. Sgrolli, N. Imlyhen, J. Volkman, A.M. Raspolli-Galletti, P. Serp, Molecular Catalysis, 438 (2017) 143-151.

22. M.M. Villaverde, T. F. Garetto, A. J. Marchi, Catal. Commun., 58 (2015) 6-10.

23. D. Scholz, C. Aellig, I. Hermans, ChemSusChem, 7 (2014) 268-275.

24. J.F. Moulder, W.F. Stickle, P.E. Sobol, K.D. Bomben, Standard Spectra for Identification and Interpretation of XPS data, Perkin Elmer, Eden Prairie, MN,1992.

25. E. Moretti, M. Lenarda, P. Riello, L. Storaro, A. Talon, R. Frattina, A. Reyes-Carmona, A. Jiménez-López, E. Rodríguez-Castellón, Appl. Catal. B: Environ., 129 (2013) 556-565.

26. A.P. Grosvenor, B.A. Kobe, M.C. Biesinger, N.S. McIntyre, Surf. Interface Anal., 36 (2004) 1564-1574.

27. T. Yamashita, P. Hayes, Appl. Surf. Sci., 254 (2008) 2441-2449. 
28. J.M. Rubio-Caballero, S. Saravanamurugan, P. Maireles-Torres, A. Riisager, Catal. Today, 234 (2014) 233-236.

29. W. Gong, C. Chen, Y. Zhang, H. Zhou, H. Wang, H. Zhang, Y. Zhang, G. Wang, H. Zhao, ACS Sustainable Chem. Eng., 5 (2017) 2172-2180.

30. J. Zhang, J. Chen, ACS Sustainable Chem. Eng., 5 (2017) 5982-5993.

31. H. Gómez Bernal, L. Bernazzani, A.M. Raspolli Galletti, Green Chem., 16 (2014) 37343740 .

32. H. Gómez Bernal, A.M. Raspolli Galletti, G. Garbarino, G. Busca, E. Finocchio, Appl. Catal. A: Gen., 502 (2015) 388-398.

33. Z.H. Zhang, K. Dong, Z. B. Zhao, ChemSusChem, 4 (2011) 112-118.

34. G.M. González Maldonado, R.S. Assary, J. Dumesic, L.A. Curtiss, Energy Environ. Sci., 5 (2012) 8990-8997.

35. G. Wang, Z. Zhang, L. Song, Green Chem., 16 (2014) 1436-1443.

36. E. de Jong, T. Vijlbrief, R. Hijkoop, G. J. M. Gruter and J. C. van der Waal, Biomass Bioenergy, 36 (2012) 151-159.

37. A.J.J.E. Eerhart, W.J.J. Huijgen, R.J.H. Grisel, J.C. Van der Waal, E. de Jong, A.D.S. Dias, A.P.C. Faaij, M.K. Patel, RSC Adv., 4 (2014) 3536-3549.

38. M.A. Tejero, E. Ramírez, C. Fité, J. Tejero, F. Cunill, Appl. Catal. A: Gen., 517 (2016) 5666.

39. R. Bringué, E. Ramírez, M. Iborra, J. Tejero, F. Cunill, J. Catal., 304 (2013) 7-21.

40. D. Zhao, P. Prinsen, Y. Wang, W. Ouyang, F. Delbecq, C. Len, R. Luque, ACS Sustainable Chem. Eng., 6 (2018) 6901-6909.

41. L. Jiang, L. Zhou, J. Chao, H. Zhao, T. Lu, Y. Su, X. Yang, J. Xu, Appl. Catal. B: Environ., 220 (2018) 589-596.

42. Y.B. Huang, T. Yang, Y.T. Lin, Y.Z. Zhu, L.C. Li, H. Pan, Green Chem., 20 (2018) 13231334. 